\title{
Ecological innovations for regional sustainable development: an empirical study
}

\author{
Maksim Kurganov* and Elena Tretiakova \\ Perm State National Research University, 15, Bukireva St., Perm, 614990, Russian Federation
}

\begin{abstract}
The article is devoted to the study of sustainable regional development from the perspective of the value-driven approach and the assessment of the environmental innovations impact on the sustainability of the regional development. The methodological framework included the sustainable development concept, the main provisions of the regional economy, the rational use of natural resources principles and the value-driven management. The study determined the level of realization of the values and interests of the population, the business community and authorities in the economic, environmental and social spheres. It has been established that achieving sustainable development goals at the regional level requires reducing the environmental intensity of enterprises, reducing the volume of pollution of the atmosphere and water resources, as well as the volume of generated production and consumption waste. The regional environmental innovations implementation is considered the main driver of positive changes in the field of natural resource management and environmental protection. Using econometric modeling, an assessment was made of the impact of environmental innovations and factors of the regional environment on the level of realization of the sustainable development values in the context of key stakeholders of the territories and the degree of coordination of their interests, as well as on key indicators of the economic activity. The environmental innovations importance in the regional sustainable development is mathematically proved and the environmental innovations specificity in the context of improving regional policy is characterized.
\end{abstract}

\section{Theoretical and methodological provisions of the research}

\subsection{Relevance of the research}

Against the background of the aggravation of the economic, social and environmental problems of the regions in recent years, the concept of sustainable development (hereinafter the "SD") is gaining special relevance. The importance of the regional vector of research on the basic provisions of the concept of SD is due to the need to balance the implementation of economic, environmental and social imperatives in combination with the improvement of methods and approaches to the management of regional systems [1].

Despite the fact that the concept of SD covers the most pressing problems in the social, economic and environmental spheres, it does not consider the problems of coordinating the goals and interests of the population, the business community and government bodies interacting in the process of economic relations. This impedes the achievement of socio-ecological-economic balance in the development of territories. Coordination of the priorities and interests of these stakeholders is fundamentally necessary, since the rates of socioeconomic development, natural resource potential, and the level of infrastructure development in the regions are different. This significantly affects the structure of economic relations between the stakeholders of the territories, the characteristics of their behavior and readiness to compromise.

Overcoming this barrier may be associated with the use of a value-based approach to management, which is acquiring an increasingly significant role in the complex of modern methods of managing socio-economic systems of various levels. Thus, identifying the goals and interests of stakeholders, determining the values received by stakeholders, assessing the degree of their coherence with each other and correlating them with the results of the activities of subjects of economic relations will take into account the high level of environmental uncertainty and determine key areas of managerial influence, reducing the likelihood of antagonistic behavior towards each other.

Let us emphasize the fact that the results of studies in the field of sustainability of regional development indicate a relatively low level of achievement of goals in the context of the ecological component. As a rule, the key reasons for this phenomenon are: a high level of environmental intensity of enterprises operating in the region; large volume of generated production and consumption waste; rejection of resource-saving technologies and switching to circular business models in favor of traditional and well-established approaches to conducting production activities (see [2-4]).

One of the solutions to these problems is to stimulate economic agents to create and use technological and social innovations aimed at protecting the environment.

\footnotetext{
Corresponding author: kurganovma@gmail.com
} 
The modern studies note that environmental innovations are a tool that ensures the natural resources management and creates environmental values and behavioral attitudes of key regional stakeholders in the context of the economy co- development $[5,6]$. In the given context, it is interesting to study the role of environmental innovations in the SD of the region and the realization of the values and interests of the population, the business community and regional authorities.

Thus, the purpose of the study is to assess the environmental innovations impact on the level of the key regional stakeholders SD values realization.

\subsection{Description of the methodological toolkit}

To achieve the stated goal, a methodology was developed that includes three stages: (1) conducting an integral assessment of SD from the perspective of a value-driven approach; (2) identification and analysis of imbalances in the level of value realization; (3) analysis of the environmental innovations role in the regional SD and the values and interests of economic agents realization.

At the first stage of the study, a set of indicators was formed that characterize the interests of the population, the business community and the state in the economic, environmental and social spheres. When selecting indicators, the following principles were taken into account:

- the indicator substantively characterizes the manifestation of the stakeholder's value;

dynamics;

- the indicator allows assessing SD in

- the indicator allows characterizing the SD level of a particular region;

- statistical information about the indicator should be available in open official sources.

The selection of indicators resulted in the formation of a statistical base that includes time series for 51 indicators for the period from 2010 to 2018 .

For further integral assessment, all indicators were standardized and, on their basis, nine group indices were calculated by computing a multidimensional average value in the context of three types of stakeholders and three types of values, the value of each of which comprehensively characterizes the level of implementation of each type of value for each regional stakeholder.

The calculated group indices served as the basis for calculating integral indices using the arithmetic mean of three group indices (in the context of SD components and in the context of regional stakeholders), which enabled a comprehensive characterization of the implementation degree of the SD values.

At the second stage of the study, the coefficients of variation between the values of the integral indices were calculated. This procedure allowed identifying the disparities in the level of realization of values (the value of the coefficient is more than 0.33 ) and quantifying the degree of consistency of values and interests of SD.
At the final stage, a regression analysis was carried out, which allowed determining the strength of the relationship and influence of environmental innovations and other environmental factors of the regional environment on the level of SD of the region and the degree of realization of the interests of the population, authorities and the business community.

Thus, the proposed methodological toolkit is focused on a comprehensive study of the role of environmental innovations in the SD of the region, taking into account the goals, interests and values with which the stakeholders enter into economic relations.

\section{Empirical research results}

\subsection{Assessment of the level of implementation of sustainable development values}

The methodological toolkit was tested on the regions of the Volga and Ural federal districts. It should be noted that the Tyumen region and its constituent autonomous okrugs were excluded from the sample due to the lack of statistical indicators sufficient for empirical research.

Tables 1 and 2 contain information on the level of realization of economic and environmental values of the population, business and government (values of group indices), as well as integral indices characterizing the degree of achievement of SD goals for each of the analyzed components.

Noteworthy is the relatively low level of implementation of the environmental values of the business community and government bodies. According to the results of the study, the most negative impact on the level of implementation of the environmental values of a business is exerted by relatively high indicators of the volume of fresh water use for industrial purposes, the volume of emissions of air pollutants and the volume of polluted wastewater discharge. This indicates the need to improve the technological base and search for innovative solutions that reduce the negative impact of enterprises on the environment.

The low level of implementation of the environmental values of regional authorities is due to the relatively high volumes of industrial and consumer wastes generation per capita, as well as the relatively low share of current expenditures on environmental protection in the GRP. In some regions (for example, in the Udmurt Republic and the Republic of Mari El), relatively low volumes of reforestation were recorded, correlated with the volume of timber harvesting, and very small volumes of utilized production and consumption wastes.

The environmental values of the population are also characterized by a low level of implementation in most of the analyzed subjects, despite positive developments in the Republic of Mari El, Perm Territory, Nizhny Novgorod and Orenburg regions. During the study, it was found that these positive trends are due to a significant decrease in the proportion of air samples with an excess of the MPC by 2018 and an increase in the proportion of the population supplied by with drinking 
water that meets all health-based standards. The worst situation is observed in the Kurgan region.

Dwelling on the analysis of the economic values of the stakeholders of the territories, let us pay attention to the low level of the authorities' economic values realization. It is also characterized by minor fluctuations in most of the regions under consideration. The leaders in the level of population economic values realization are the Republic of Tatarstan, the Sverdlovsk, Nizhny Novgorod regions and the Perm Territory. At the same time, downward trends in the realization of the economic values of the population were noted in the Chuvash Republic and the Chelyabinsk region. The authors identify the main reason for this trend as the growth in the proportion of population with incomes below the subsistence minimum. The lowest level of realization of the economic values of the business community was identified in the Kurgan and Orenburg regions and the Republic of Mari El. During the analyzed period, the number of regions with a high level of realization of economic values decreased from five (in 2010) to two (in 2018).

With regard to the social values of the considered stakeholders, the authors established a high level of their implementation in all analyzed regions for each economic agent (values of group indices are more than 0.7). This trend can be caused by the establishment at the federal level of social standards and social norms to ensure a decent quality of life, the implementation of federal state programs, and control over their observance at the regional level.

Thus, the SD integral assessment results based on value-driven approach confirm the trends identified in other studies on the problem under study. The level of implementation of environmental values is one of the main barriers hindering balanced socio-ecological and economical regional development.

\subsection{Analysis of the role of environmental innovations in sustainable development of the region: results of econometric modeling}

Taking into account the regional SD integral assessment results from the standpoint of the value-driven approach, as well as the results of national and international studies, the authors propose to consider the possibility of increasing the regional SD level by influencing the environmental values of the considered stakeholders.

The introduction and implementation of environmental innovations in the region is considered as a key instrument of influence, which creates conditions for the transition of regional socio-economic systems to a new qualitative level. To solve this problem, a regression analysis is carried out in the study. Based on the existing scientific base in the studied problem area, the first prerequisite for conducting econometric modeling can be designated as follows: the level of implementation of environmental values is influenced by regional environmental factors that characterize the degree and scale of management impacts to improve the situation in a particular region. It is important to emphasize that one of the most significant characteristics of the regional environment factors is controllability.

Therefore, in this study the following is considered as factors of the regional environment:

- the share of organizations that carried out environmental innovations in the reporting year in the total number of organizations surveyed, $\%$;

- the share of investments in fixed assets aimed at environmental protection and rational use of natural resources in GRP, \%;

- the number of violations in the field of environmental management.

The second prerequisite for the construction of economic and mathematical models is that the particular stakeholder environmental values realization level depends on the degree of goals achievement and interests satisfaction of the other economic agents. In other words, the environmental values of the population, business community and government are interrelated.

In view of the above, the analytical presentation of econometric models takes the following form:

$E C O L_{-} I N D_{\text {people }}=f\left(I N D_{\text {ecol }}, X_{\text {region }}\right)+\varepsilon$,

$E C O L_{-} I N D_{\text {business }}=f\left(I N D_{\text {ecol }}, X_{\text {region }}\right)+\varepsilon$

$E C O L_{-} I N D_{\text {government }}=f\left(I N D_{\text {ecol }}, X_{\text {region }}\right)+\varepsilon$,

where:

$E C O L_{-} I N D_{\text {people }}$ is group index characterizing the level of implementation of the environmental values of the population;

$E C O L_{-} I N D_{\text {business }}$ is the group index characterizing the level of implementation of the environmental values of the business community;

ECOL_IND $D_{\text {government }}$ is the group index characterizing the level of implementation of the environmental values of the authorities;

$I N D_{\text {ecol }}$ is the vector of variables reflecting group indices for the ecological component of other stakeholders;

$X_{\text {region }}$ is the vector of variables reflecting the state of the regional environment in terms of the ecological component;

$\varepsilon$ is the regression error. 
Table 1. Group and integral indices characterizing the level of implementation of economic values*

\begin{tabular}{|c|c|c|c|c|c|c|c|c|c|c|c|}
\hline \multirow{3}{*}{ Region } & \multicolumn{9}{|c|}{ ECONOMIC VALUES } & \multirow{2}{*}{\multicolumn{2}{|c|}{$\begin{array}{c}\text { Integral index } \\
\text { (economic values) }\end{array}$}} \\
\hline & \multicolumn{3}{|c|}{ Population } & \multicolumn{3}{|c|}{ Business } & \multicolumn{3}{|c|}{ Authorities } & & \\
\hline & 2010 & 2018 & $\Delta * *$ & 2010 & 2018 & $\Delta * *$ & 2010 & 2018 & $\Delta^{* *}$ & 2010 & 2018 \\
\hline $\begin{array}{l}\text { Republic of } \\
\text { Bashkortostan }\end{array}$ & 0.65 & 0.62 & $\downarrow$ & 0.72 & 0.58 & $\downarrow$ & 0.53 & $\underline{0.40}$ & $\downarrow$ & 0.63 & 0.53 \\
\hline Mari El Republic & 0.59 & 0.56 & $\downarrow$ & 0.49 & $\underline{0.47}$ & $\rightarrow$ & $\underline{0.43}$ & $\underline{0.42}$ & $\rightarrow$ & 0.50 & $\underline{0.48}$ \\
\hline $\begin{array}{l}\text { The Republic of } \\
\text { Mordovia }\end{array}$ & 0.55 & 0.55 & $\rightarrow$ & 0.62 & 0.59 & $\rightarrow$ & 0.51 & $\underline{0.48}$ & $\downarrow$ & 0.56 & 0.53 \\
\hline Republic of Tatarstan & 0.92 & 0.92 & $\rightarrow$ & 0.78 & 0.77 & $\rightarrow$ & 0.67 & 0.64 & $\downarrow$ & 0.78 & 0.77 \\
\hline Udmurtia & 0.66 & 0.63 & $\downarrow$ & 0.55 & 0.56 & $\uparrow$ & 0.53 & $\underline{0.39}$ & $\downarrow$ & 0.58 & 0.52 \\
\hline Chuvash Republic & 0.65 & 0.58 & $\downarrow$ & 0.53 & 0.58 & $\uparrow$ & $\underline{0.37}$ & 0.34 & $\downarrow$ & 0.51 & 0.49 \\
\hline Perm Territory & 0.70 & 0.72 & $\downarrow$ & 0.55 & 0.55 & $\uparrow$ & $\overline{0.56}$ & $\overline{0.60}$ & $\uparrow$ & 0.60 & 0.62 \\
\hline Kirov region & 0.63 & 0.60 & $\downarrow$ & 0.50 & 0.64 & $\uparrow$ & $\underline{0.42}$ & $\underline{0.40}$ & $\downarrow$ & 0.51 & 0.53 \\
\hline Nizhny Novgorod Region & 0.73 & 0.78 & $\uparrow$ & 0.86 & 0.74 & $\downarrow$ & $\overline{0.63}$ & $\overline{0.58}$ & $\downarrow$ & 0.73 & 0.69 \\
\hline Orenburg region & 0.55 & 0.56 & $\uparrow$ & 0.63 & $\underline{0.46}$ & $\downarrow$ & 0.58 & $\underline{0.49}$ & $\downarrow$ & 0.58 & 0.50 \\
\hline Penza region & 0.59 & 0.60 & $\uparrow$ & 0.52 & $\overline{0.53}$ & $\uparrow$ & $\underline{0.40}$ & $\overline{\underline{0.41}}$ & $\rightarrow$ & 0.50 & 0.51 \\
\hline Samara Region & 0.69 & 0.69 & $\rightarrow$ & 0.80 & 0.61 & $\downarrow$ & 0.58 & $\underline{0.49}$ & $\downarrow$ & 0.68 & 0.59 \\
\hline Saratov region & 0.62 & 0.58 & $\downarrow$ & 0.72 & 0.52 & $\downarrow$ & 0.44 & $\overline{0.41}$ & $\downarrow$ & 0.58 & 0.50 \\
\hline Ulyanovsk region & 0.63 & 0.58 & $\downarrow$ & 0.63 & 0.60 & $\rightarrow$ & $\underline{0.43}$ & 0.50 & $\uparrow$ & 0.56 & 0.56 \\
\hline Kurgan region & 0.54 & 0.49 & $\downarrow$ & 0.53 & $\underline{0.45}$ & $\downarrow$ & $\underline{0.43}$ & $\underline{0.34}$ & $\downarrow$ & 0.50 & $\underline{0.42}$ \\
\hline Sverdlovsk region & 0.88 & 0.81 & $\downarrow$ & 0.60 & $\overline{0.53}$ & $\downarrow$ & $\overline{0.51}$ & $\overline{0.53}$ & $\uparrow$ & 0.64 & $\overline{0.61}$ \\
\hline Chelyabinsk region & 0.70 & 0.62 & $\downarrow$ & 0.69 & 0.58 & $\downarrow$ & 0.54 & 0.50 & $\downarrow$ & 0.64 & 0.56 \\
\hline
\end{tabular}

$*$ the gray filling in the table indicates the values of the indices, which indicate a high level of realization of values (the values of the indices are 0.7 and higher); the underscore indicates the values of the indices that characterize the low level of realization of values (the values of the indices are below 0.5 ).

** direction of arrows characterizes the direction of the trend during 2010-2018:

$\uparrow$ - ascending; $\downarrow$ - descending; $\rightarrow$ - horizontal

Table 2. Group and integral indices characterizing the level of implementation of environmental values *.

\begin{tabular}{|c|c|c|c|c|c|c|c|c|c|c|c|}
\hline \multirow{3}{*}{ Region } & \multicolumn{9}{|c|}{ ENVIRONMENTAL VALUES } & \multirow{2}{*}{\multicolumn{2}{|c|}{$\begin{array}{c}\text { Integral index } \\
\text { (environmental values) }\end{array}$}} \\
\hline & \multicolumn{3}{|c|}{ Population } & \multicolumn{3}{|c|}{ Business } & \multicolumn{3}{|c|}{ Authorities } & & \\
\hline & 2010 & 2018 & $\Delta^{* *}$ & 2010 & 2018 & $\Delta * *$ & 2010 & 2018 & $\Delta^{* *}$ & 2010 & 2018 \\
\hline $\begin{array}{l}\text { Republic of } \\
\text { Bashkortostan }\end{array}$ & 0.68 & $\underline{0.38}$ & $\downarrow$ & $\underline{0.37}$ & $\underline{0.33}$ & $\downarrow$ & $\underline{0.39}$ & $\underline{0.36}$ & $\downarrow$ & $\underline{0.46}$ & $\underline{0.36}$ \\
\hline Mari El Republic & 0.56 & 0.93 & $\uparrow$ & $\underline{0.25}$ & $\underline{0.25}$ & $\rightarrow$ & $\underline{0.19}$ & $\underline{0.20}$ & $\uparrow$ & $\underline{0.30}$ & $\underline{0.36}$ \\
\hline $\begin{array}{l}\text { The Republic of } \\
\text { Mordovia }\end{array}$ & 0.56 & 0.62 & $\uparrow$ & $\underline{0.37}$ & 0.42 & $\uparrow$ & $\underline{0.43}$ & $\underline{0.31}$ & $\downarrow$ & $\underline{0.45}$ & $\underline{0.43}$ \\
\hline Republic of Tatarstan & $\underline{0.42}$ & $\underline{0.44}$ & $\uparrow$ & 0.52 & 0.43 & $\downarrow$ & $\underline{0.33}$ & 0.24 & $\downarrow$ & 0.42 & $\underline{0.36}$ \\
\hline Udmurtia & 0.47 & $\underline{0.38}$ & $\downarrow$ & 0.29 & 0.24 & $\downarrow$ & 0.21 & $\underline{0.16}$ & $\uparrow$ & $\underline{0.30}$ & $\underline{0.25}$ \\
\hline Chuvash Republic & 0.65 & $\underline{0.48}$ & $\downarrow$ & $\underline{0.44}$ & $\underline{0.38}$ & $\rightarrow$ & $\underline{0.33}$ & 0.25 & $\downarrow$ & $\underline{0.45}$ & $\underline{0.36}$ \\
\hline Perm Territory & $\underline{0.36}$ & 0.63 & $\uparrow$ & 0.24 & $\underline{0.23}$ & $\downarrow$ & $\underline{0.45}$ & $\underline{0.40}$ & $\downarrow$ & $\underline{0.34}$ & $\underline{0.39}$ \\
\hline Kirov region & $\overline{0.47}$ & 0.56 & $\uparrow$ & $\underline{0.23}$ & $\overline{0.22}$ & $\downarrow$ & $\underline{0.30}$ & $\overline{0.35}$ & $\uparrow$ & $\overline{0.32}$ & $\overline{0.35}$ \\
\hline Nizhny Novgorod Region & $\underline{0.35}$ & 0.67 & $\uparrow$ & 0.61 & 0.62 & $\rightarrow$ & $\underline{0.31}$ & $\underline{0.28}$ & $\downarrow$ & $\underline{0.40}$ & $\underline{0.49}$ \\
\hline Orenburg region & 0.52 & 0.96 & $\uparrow$ & $\underline{0.19}$ & $\underline{0.19}$ & $\uparrow$ & 0.58 & 0.58 & $\uparrow$ & $\underline{0.39}$ & $\underline{0.47}$ \\
\hline Penza region & 0.57 & 0.61 & $\uparrow$ & 0.26 & 0.22 & $\downarrow$ & $\underline{0.22}$ & 0.22 & $\uparrow$ & 0.32 & 0.31 \\
\hline Samara Region & 0.51 & 0.62 & $\uparrow$ & 0.34 & 0.31 & $\downarrow$ & 0.43 & 0.32 & $\downarrow$ & 0.42 & $\underline{0.40}$ \\
\hline Saratov region & 0.41 & $\underline{0.38}$ & $\rightarrow$ & 0.55 & 0.37 & $\downarrow$ & 0.37 & 0.34 & $\rightarrow$ & 0.44 & 0.36 \\
\hline Ulyanovsk region & 0.51 & $\underline{0.40}$ & $\downarrow$ & $\underline{0.30}$ & $\underline{0.29}$ & $\rightarrow$ & 0.41 & 0.26 & $\downarrow$ & $\underline{0.40}$ & $\underline{0.31}$ \\
\hline Kurgan region & $\underline{0.27}$ & 0.30 & $\uparrow$ & 0.27 & 0.24 & $\downarrow$ & 0.41 & 0.27 & $\downarrow$ & 0.31 & $\underline{0.27}$ \\
\hline Sverdlovsk region & $\underline{0.39}$ & $\underline{0.40}$ & $\rightarrow$ & $\underline{0.36}$ & $\underline{0.40}$ & $\uparrow$ & 0.67 & 0.55 & $\downarrow$ & $\underline{0.45}$ & $\underline{0.44}$ \\
\hline Chelyabinsk region & $\underline{0.43}$ & $\underline{0.35}$ & $\downarrow$ & $\underline{0.30}$ & $\underline{0.26}$ & $\downarrow$ & 0.53 & 0.54 & $\uparrow$ & $\underline{0.41}$ & $\underline{0.37}$ \\
\hline
\end{tabular}

$*$ the gray filling in the table indicates the values of the indices, which indicate a high level of realization of values (the values of the indices are 0.7 and higher); the underscore indicates the values of the indices that characterize the low level of realization of values (the values of the indices are below 0.5 ).

** direction of arrows characterizes the direction of the trend during 2010-2018:

$\uparrow$ - ascending; $\downarrow$ - descending; $\rightarrow$ - horizontal 
Thus, the regression analysis is based on panel data on the factors of the regional environment and the level of implementation of environmental values by stakeholders for the period from 2010 to 2018. To ensure the possibility of comparing the simulation results and reducing the statistical space, the absolute and index variables were logarithmized.

Regression analysis was performed using the construction of panel data models with fixed effects. The simulation results are presented in Table 3.

Table 3. Results of econometric modeling

\begin{tabular}{|c|c|c|c|}
\hline $\begin{array}{c}\text { Independent } \\
\text { variable }\end{array}$ & $\begin{array}{c}l \_E C O L \_P \\
\text { EOPLE_I } \\
\text { ND }\end{array}$ & $\begin{array}{l}\text { l_ECOL_B } \\
\text { US_IND }\end{array}$ & $\begin{array}{l}l_{\text {_ECOL_E }} \\
\text { GOV_IND }\end{array}$ \\
\hline l_ECOL_VIOLAT & $\begin{array}{l}-0.11 \\
(0.03)\end{array}$ & $\begin{array}{c}0.02 \\
(0.02) \\
\end{array}$ & $\begin{array}{c}0.02 \\
(0.02) \\
\end{array}$ \\
\hline ECOL_INN & $\begin{array}{c}-0.02^{* *} \\
(0.00) \\
\end{array}$ & - & $\begin{array}{c}0.02^{* * * *} \\
(0.02)\end{array}$ \\
\hline ECOL_INN (-1) & - & $\begin{array}{l}0.01 * \\
(0.00) \\
\end{array}$ & - \\
\hline INV_EP & $\begin{array}{l}-0.09 \\
(0.06) \\
\end{array}$ & $\begin{array}{c}0.01 \\
(0.03) \\
\end{array}$ & $\begin{array}{c}0.04 \\
(0.03) \\
\end{array}$ \\
\hline 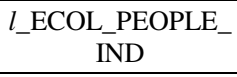 & - & $\begin{array}{c}0.05 \\
(0.03) \\
\end{array}$ & $\begin{array}{c}0.09 \\
(0.06) \\
\end{array}$ \\
\hline l_ECOL_BUS_IND & $\begin{array}{c}0.19 \\
(0.12) \\
\end{array}$ & - & $\begin{array}{c}0.04 \\
(0.11) \\
\end{array}$ \\
\hline $\begin{array}{c}l_{-} \text {ECOL_GOV_IN } \\
\text { D }\end{array}$ & $\begin{array}{c}0.23 \\
(0.15) \\
\end{array}$ & $\begin{array}{c}0.01 \\
(0.04) \\
\end{array}$ & - \\
\hline Const & $\begin{array}{l}-0.13^{*} \\
(0.31) \\
\end{array}$ & $\begin{array}{c}-1.27 * * * \\
(0.15) \\
\end{array}$ & $-1.16^{* * *}$ \\
\hline$R^{2}$ & 0.74 & 0.95 & 0.89 \\
\hline $\begin{array}{c}\text { p-value for F- } \\
\text { statistics }\end{array}$ & 0.00 & 0.00 & 0.00 \\
\hline $\begin{array}{l}\text { Number of } \\
\text { observations }\end{array}$ & 136 & 119 & 136 \\
\hline
\end{tabular}

Based on the analysis performed, a number of conclusions can be drawn. First, the synergy effect in the context of the environmental values of the population, business community and government authorities was not found, which indicates the need to influence the factors of the regional environment.

Secondly, it was established that there is a relationship between the level of implementation of environmental values by key stakeholders in the region and the number of organizations that carry out environmental innovations (ECOL_INN). Consequently, the improvement of innovation policy in the field of environmental protection can become one of the drivers for increasing the level of sustainability of regional development.

Third, it was revealed that there is a direct relationship between the number of organizations implementing environmental innovations and the level of realization of environmental values by the business community (with a lag of one year) and authorities. In turn, the relationship of the specified independent variable with the population environmental values realization degree is inverse. This finding can be explained by the fact that business and government bodies are the direct subjects of the introduction of any kind of innovation, as well as the owners of investment resources for the development of the innovation base in the region. The population, in turn, does not have enough resources and tools to influence the process of launching environmental innovations. Thus, the results of regression analysis prove the existence of a problem associated with a decrease in the number of organizations implementing environmental innovations, which prevents the creation of environmentally friendly living conditions.

In order to more comprehensively assess the identified patterns, it is necessary to assess the impact of environmental innovations on the level of consistency of stakeholders' interests, GRP per capita and on the investment potential of the region. For this, three equations were built for each of the indicated dependent variables without combining them into a system of equations:

$$
\begin{gathered}
\text { lALIG_AGENTS }=f\left(X_{\text {region }}\right)+\varepsilon, \\
l G R P=f\left(X_{\text {region }}\right)+\varepsilon, \\
\text { INV_POTEN }=f\left(X_{\text {region }}\right)+\varepsilon,
\end{gathered}
$$

where:

IALIG_AGENTS is the logarithmic value of the level of consistency of interests of stakeholders in the context of SD of the region;

$l G R P$ is the logarithmic value of GRP per capita;

INV_POTEN is the share of the investment potential of a particular region in the all-Russian potential in percent;

$X_{\text {region }}$ is the vector of variables reflecting the state of the regional environment in terms of the ecological component;

$\varepsilon$ is the regression error.

Table 4 contains the results of building regression models and criteria for their quality.

The results of the regression analysis presented in Table 4 indicate a significant impact of environmental innovations on the level of consistency of values of the interests of key stakeholders in the region and indicators of the economic performance of the territories as a whole.

In particular, attention is drawn to the inverse relationship between the level of GRP per capita and the number of organizations carrying out environmental innovations, along with the volume of investments in fixed assets aimed at protecting the environment (INV_EP). This pattern can be explained by the fact that increasing the volume of GRP on the existing technological base, which is harmful to the environment, is impossible without investment in the development of new energy-saving and green production technologies with a subsequent transition to environmentally friendly business models. 
Table 4. Assessment of the influence of factors of the regional environment on key indicators of regional development

\begin{tabular}{|c|c|c|c|}
\hline $\begin{array}{c}\text { Independent } \\
\text { variable }\end{array}$ & $\begin{array}{c}\text { l_ALIG_ } \\
\text { AGENTS }\end{array}$ & $l_{- \text {GRP }}$ & $\begin{array}{c}\text { INV_POTE } \\
\mathrm{N}\end{array}$ \\
\hline $\begin{array}{c}l_{\text {_ECOL_VIOLA }} \\
\text { T }\end{array}$ & $\begin{array}{c}-0.00 \\
(0.03)\end{array}$ & $\begin{array}{c}-0.04 \\
(0.03)\end{array}$ & $\begin{array}{c}0.01 \\
(0.00)\end{array}$ \\
\hline ECOL_INN & $\begin{array}{c}-0.01^{* *} \\
(0.00)\end{array}$ & $\begin{array}{c}-0.07^{* * *} \\
(0.00)\end{array}$ & $\begin{array}{c}0.01^{* *} \\
(0.02)\end{array}$ \\
\hline INV_EP & $\begin{array}{c}-0.02 \\
(0.01)\end{array}$ & $\begin{array}{c}-0.11^{* *} \\
(0.04)\end{array}$ & $\begin{array}{c}0.02 \\
(0.02)\end{array}$ \\
\hline Const & $\begin{array}{c}-0.18^{* *} \\
(0.3)\end{array}$ & $\begin{array}{c}-13.01^{* * *} \\
(0.2)\end{array}$ & $\begin{array}{c}1.2 * * * \\
(0.03)\end{array}$ \\
\hline$R^{2}$ & 0.81 & 0.84 & 0.9 \\
\hline $\begin{array}{c}\text { p-value for F- } \\
\text { statistics }\end{array}$ & 0.00 & 0.00 & 0.00 \\
\hline $\begin{array}{c}\text { Number of } \\
\text { observations }\end{array}$ & 136 & 136 & 136 \\
\hline
\end{tabular}

At the same time, it was found that an increase in the number of environmental innovations in the region favors the regional investment potential development, and also reduces the disproportions in the level of implementation of the values of the population, the business community and government bodies.

Summing up, we can unequivocally speak about the significant role of environmental innovations in the regional SD. The results of the study proved that the use of green economy tools has a positive impact not only on the consistency of goals and interests of economic agents, but is also one of the key factors in attracting investment resources and improving the investment climate of territories.

\section{Environmental innovation as a tool for increasing the sustainability of regional development}

The key purpose of green innovation is to reduce the destructive impact on the environment and natural resources from economic activities in the region. In this case, an understanding of the main vectors of managerial impact and directions for improving regional policy plays a special role. The introduction and implementation of environmental innovations can cover various spheres of society, which is fully consistent with the goals of SD [5, 7]:

- building;

- energy;

- agriculture and reforestation;

- industry;

- tourism;

- transport infrastructure;

- waste treatment;

- water supply and water resources;

- climate change.

It should also be noted that the content of environmental innovations and the nature of their impact on the level of sustainable regional development depends on the type of innovations themselves. In this context, it is customary to distinguish the following: technologies for environmental protection (for example, technologies for reducing emissions of air pollutants), organizational eco-innovations (for example, the formation of "green" supply chains); innovative products and services aimed at improving the environmental conditions of life, as well as innovations in the field of improving regional ecosystems (for example, alternative methods of production) [8].

Since the expected benefits and effects from the introduction of environmental innovations in the region are characterized by both technological and nontechnological changes, the choice of instruments for improving regional policy in the field of SD should take into account the existing resource base and existing barriers to the implementation of green innovations. In particular, [9]:

- technological barriers caused by the complexity of developing innovative products and technologies due to the lack of environmentally friendly materials;

- financial barriers associated with the high cost of research in the field of environmental technologies and the difficulty of forecasting costs;

- barriers associated with the lack of highly qualified personnel;

- $\quad$ barriers associated with a high degree of volatility in consumer preferences and a well-established environmental mentality;

- management barriers caused by the resistance of enterprises and the need for network and intersectoral interaction.

Overcoming these barriers, according to the results of the study, is possible when influencing the factors of the regional environment. To achieve the SD goals and increase the realization level of the population, business community and authorities values, it is necessary to ensure diversification of funding sources, to form a socio-ecological identity among all stakeholders in the region, to stimulate consumer and investment demand for environmental innovations created in the region with the help of institutional measures of the state policy [10].

Summarizing the results obtained, it is important to emphasize that despite the growth of socio-economic and environmental costs associated with the search, development and implementation of green innovations in the economic activities of subjects of economic relations, the long-term effects of the implementation of environmental innovations have a positive impact on the SD of territories. The study showed the importance and necessity of stimulating economic agents to create green innovations, which will ensure an increase in the level of coherence of interests and values of all stakeholders and a balance of goals in the economic, environmental and social spheres. 


\section{References}

1. M.A. Kurganov, E.A.Tretyakova. Journal of New Economy. 4, 104-130. (2020).

2. E. Holden, K. Linnerud, D. Banister. Global Environmental Change 26, 130-139. (2014).

3. M. Howes, L. Wortley, R. Potts, A. DedekorkutHowes, S. Serrao-Neumann, J. Davidson, P. Nunn. Sustainability (Switzerland). 9. (2017).

4. M. L. Graymore, N. G. Sipe, R. E. Rickson. Ecological Economics. 3, 362-372. (2008).

5. T. Tambovceva, M. Tereshina, V. Samarina. Engineering for Rural Development. 1832-1839. (2019).

6. J.H. Jo, T.W. Roh, S. Kim, Y. C. Youn, M. S. Park, K. J. Han, E. K. Jang. Sustainability. 7, 1682016835. (2015).

7. M. Park, R. Bleischwitz, K. Han, E. Jang E., J. Joo. Comparing eco-innovation indices: ASEM ecoinnovation index \& eco-innovation scoreboard. (ASEIC and University College London, 2016).

8. A. Arundel, R. Kemp. Measuring eco-innovation. (Maastricht: UM Merit, 2009).

9. N. Yu. Arefyeva. EurAsian Journal of BioSciences. The 12, 263-269. (2018).

10. A. Sarkar, European Journal of SD 2 (2013). 